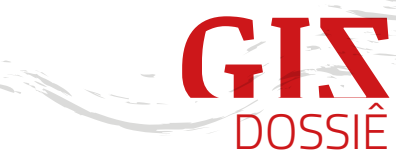

Dol

https://dx.doi.org/10.11606/ issn.2525-3123.gis.2019.162333

ORCID

\section{PERFORMANCES NO PLANETA BREAK ${ }^{1}$}

\section{OTÁVIO RAPOSO}

Centro de Investigação e Estudos de Sociologia,

Instituto Universitário de Lisboa (CIES-IUL), Lisboa,

Portugal, 1649-026 - cies@iscte-iul.pt

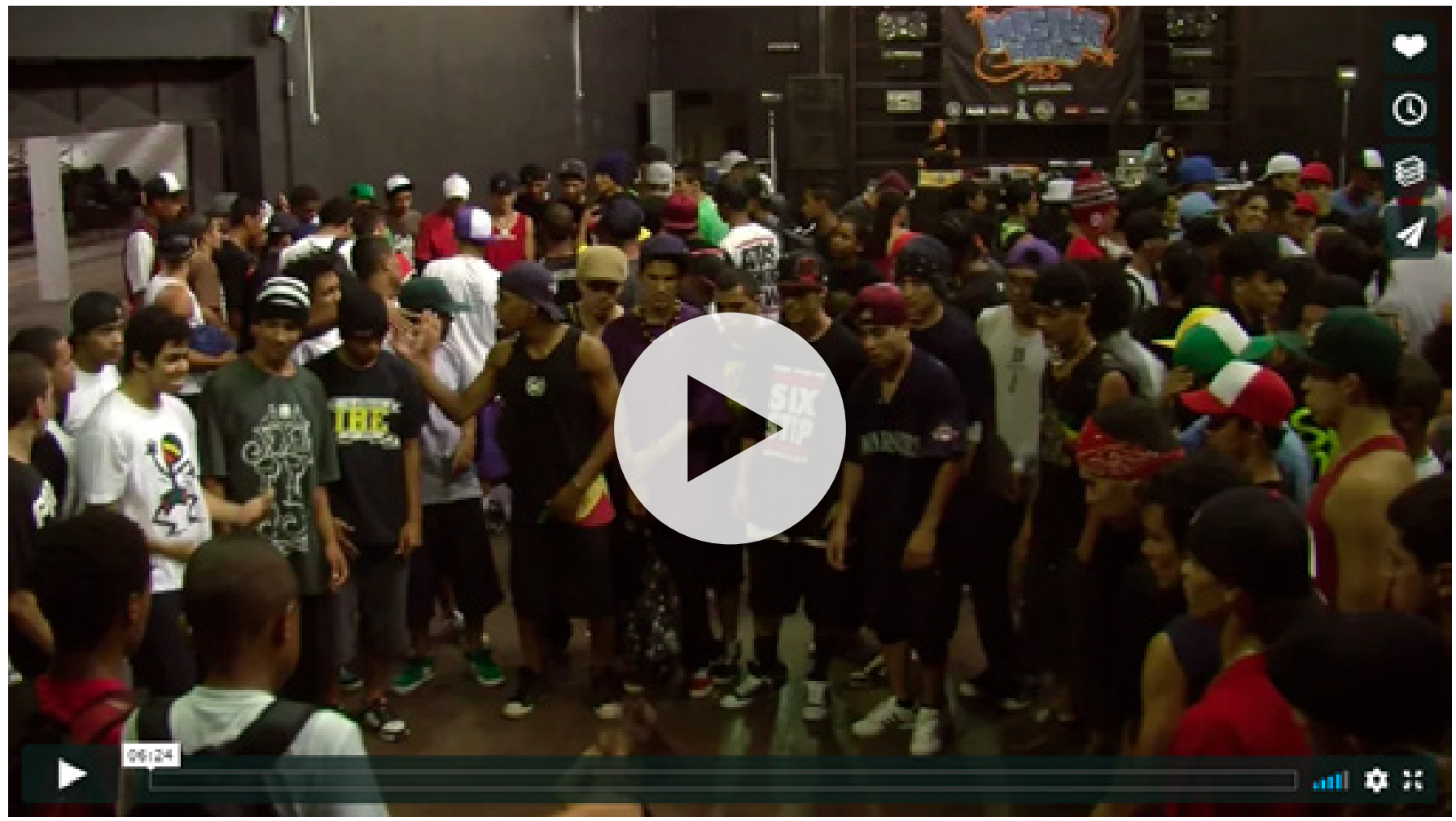

\title{
PERFORMANCES NO PLANETA BREAK
}

6'24", 2018

1. Este trabalho é fruto da minha pesquisa de doutorado em Antropologia (Raposo 2013), que também teve como resultado o documentário A galera (Raposo 2016). Foi financiada pela Fundação para a Ciência e Tecnologia (FCT) e desenvolvida no quadro institucional do Instituto Universitário de Lisboa (ISCTE-IUL) e do Centro de Investigação e Estudos de Sociologia (CIES-IUL). 
Os corpos balançam ao ritmo do funk e do breakbeat. A dança é acompanhada pelo bater de palmas e por olhares atentos ou de cumplicidade. os bonés de aba plana, os ténis de marca e as camisetas coloridas com símbolos ligados à "cultura hip-hop" são dominantes entre os jovens, "fachadas visuais" que corporizam a adesão ao mesmo estilo de vida (Pais 2004, 43). Afinal, não basta fazer break dance $e^{2}$ para ser $b$-boy ou $b$-girl, é preciso mostrar-se enquanto tal. Ambas as ações (fazer e mostrar-se) compõem a performance do dançarino (Schechner 2002), sendo obrigatórias na incorporação dessa identidade.

À medida que a música invade o recinto, multiplicam-se as "rodas" onde b-boys e b-girls disputam o privilégio de dançar. As performances não ultrapassam 30 segundos. Para cada "entrada", devem mostrar um conjunto de variações de movimentos, enquanto outros observam, aguardando a sua vez para entrar na roda. As apresentações são individuais e seguem a fórmula toprock - footwork - freeze $e^{3}$. Mas não há obrigatoriedade em adotar esse padrão. Muitos iniciam a dança com uma acrobacia ou movimento de giro (power moves), o que também ocorre no meio ou no final.

Diferentemente das batalhas, que, como o próprio nome indica, simulam lutas, nas rodas privilegia-se a confraternização dos dançarinos por meio da dança. Todavia, a intensa competitividade transforma algumas delas num acirrado "campo de batalha". As posturas tornam-se desafiadoras, não faltando caretas e outras expressões faciais a simular ora agressividade, ora deboche, componentes performáticos fundamentais para desestabilizar os adversários e aceder ao estatuto de melhor dançarino.

Revelam-se, a partir deste momento, complexas redes de alianças e rivalidades entre os $b$-boys, marcadas pelo incentivo a uns e a censura a outros. Numa das rodas, a provocação sobe de tom. Jovens de uma mesma $\mathrm{crew}^{4}$ defendem-se mutuamente, amparando as suas performances na roda: aplaudem, fazem gestos de encorajamento e gritam elogios. Quando qualquer outro jovem desafia um deles durante a dança, com gestos ou expressões de intimidação, todos se unem para ostracizar o adversário comum. Colocam em cena um vasto repertório de mímicas, deboches e acenos como forma de apontar os erros e desqualificar as performances dos rivais: dedos em riste, sorrisos irónicos, gritos e zombarias várias.

2. Break dance ou break é a vertente de dança do hip-hop, um movimento urbano que agrega, além desta, outras três expressões artísticas: rap, dj e grafite. Os seus dançarinos são chamados de $b$-boy ou $b$-girl.

3. O toprock é a parte da dança feita em pé numa cadência funk estilizada; os passos executados no chão, com as mãos a servir de apoio, são chamados de footwork; e o freeze é quando o dançarino "congela" um determinado movimento numa pose difícil.

4. Influenciadas pelo hip-hop, as crews são agrupamentos informais de jovens que se reveem em práticas comuns; neste caso, o break dance. 
Numa dada altura, dois b-boys entram ao mesmo tempo na roda. Na tentativa de marcar o território, um deles dança up rock, ${ }^{5}$ num combate ritmado que simula murros e facadas. 0 outro jovem gesticula para que ele se afaste do centro da roda, sendo apoiado por colegas que defendem ser a vez de "um deles" dançar. Apesar de ter recuado, o jovem encara o oponente com olhares de troça e reprovação. Agachado, aponta para o seu ouvido direito, a querer dizer que o outro dança fora de ritmo. o clima na roda estava "quente", mas chegou ao rubro quando uma música, famosa entre os dançarinos, começou a tocar. A dança torna-se mais intimista, e os jovens utilizam várias artimanhas para depreciar a qualidade do grupo concorrente. Encenam uma violência teatralizada em que tudo é válido, a não ser tocar no adversário para interferir nas suas performances.

Essa batalha, assim como as seguintes, encenavam confrontos simbólicos, em que o corpo era o veículo de expressão por excelência. Não eram simples gesticulações: comunicavam sentimentos e reclamavam valores - como solidariedade grupal, originalidade, determinação, respeito, amor pela dança - por meio de performances elaboradas. Eram rituais que celebravam a amizade, o convívio e a pertença à mesma cultura urbana. Mesmo nos momentos mais tensos, os rostos dos dançarinos mostravam uma alegria genuína, evidenciando que a violência encenada de muitos dos seus gestos em roda era de caráter essencialmente teatral, um modo de se divertirem e festejarem afinidades, no contexto de uma festa de homenagem ao hip-hop. ${ }^{6}$ São performances espetaculares cuja agressividade fazia parte de uma situação ritual específica que operava no contexto da mesma "província de significados" (Schütz 1979).

o conjunto de códigos, estéticas, posturas, gestos e movimentos realizados em roda tinha o corpo como epicentro, e a sua compreensão comum permitia que, após tensas disputas e provocações, os dançarinos se abraçassem e as brigas fossem raras. "Partilhar o sentido em jogo" era fundamental para poder entrar nessas interações (Agier 2011, 89), quando se viviam momentos liminares - fora do tempo, da estrutura e da rotina - inesquecíveis, capazes de transformar uma massa de dançarinos numa comunidade de sentido (Raposo 2014), parte integrante de uma cultura prestigiada e de escala global.

\section{REFERÊNCIAS BIBLIOGRÁFICAS}

Agier, Michel. 2011. Antropologia da Cidade: lugares, situações, movimentos. São Paulo: Terceiro Nome.

Pais, José Machado. 2004. Jovens, bandas musicais e revivalismos tribais. In Tribos Urbanas. Produção artística e identidades, ed. José Machado Pais e Leila Maria Blass, 23-55. Lisboa: Imprensa de Ciências Sociais.

5. Inspirador para os primeiros b-boys, o up rock surgiu nos anos 1960-70, como uma dança que utiliza gestos e mímicas que encenam agressões aos dançarinos adversários. 6. As filmagens foram realizadas em São Paulo, em dezembro de 2010, num dos eventos de break dance mais prestigiados do Brasil: Master Crew. 
Raposo, Otávio. 2014. "Nós representa a favela mano". B-boys da Maré superando estereótipos. Revista Antropolítica 37: 21-50.

Raposo, Otávio. 2013. Coreografias da amizade: estilos de vida e segregação entre os jovens do break dance da Maré (Rio de Janeiro). Tese de doutoramento, Instituto Universitário de Lisboa, Lisboa.

Schechner, Richard. 2002. Performance Studies: an introduction. London: Routledge.

Schütz, Alfred. 1979. Fenomenologia e Relações Sociais. Rio de Janeiro: Zahar Editora.

DOCUMENTÁRIO

Raposo, Otávio. 2016. A galera. Lisboa, Portugal, cor, 45'.

PALAVRAS-CHAVE

Performance; dança; break dance; liminaridade; vídeo.

KEYWORDS

Performance; dance; breakdancing; liminality; video.

\section{RESUMO}

As "rodas" são os locais privilegiados de troca de experiência entre os dançarinos de break dance, quando jovens de diferentes coletivos e territórios confraternizam por meio da dança. A partir da filmagem dessas "rodas" num evento de break dance, problematiza-se o ritual performático dos b-boys e das b-girls, composto por um rico repertório de movimentos, estéticas, gestos e expressões faciais. Vividas como momentos liminares, essas performances simulam ora confrontos simbólicos salpicados de violência teatralizada, ora a pertença a uma mesma cultura urbana, transformando uma massa de dançarinos numa comunidade de sentido.

\section{ABSTRACT}

The "cyphers" are the privileged places of experiences exchange between the breakdancers, when young people of diferente crews and territories socialize through dance. From the filming of theses cyphers in a break dance event I problematize the performances of b-boys and b-girls, composed of a rich repertoire of movements, aesthetics, gestures and facial expressions. Experienced as liminal moments, these performance simulate sometimes symbolic confrontations of dramatized violences, sometimes feeling of belonging to the same urban culture, transforming a mass of dancers into a sense of community.

OTÁVIO RAPOSO é pesquisador integrado do Centro de Investigação e Estudos de Sociologia (CIES-IUL) e professor auxiliar convidado do Instituto Universitário de Lisboa. Desenvolve pesquisas nas áreas de Antropologia Urbana e Culturas Juvenis que resultaram em publicações nacionais e internacionais, como os livros $O$ trabalho da arte e a arte do trabalho: circuitos criativos de artistas imigrantes em Portugal (2016) e Expressões artísticas urbanas: etnografia e criatividade em espaços atlânticos (2015). Realizou diversos documentários, entre os quais A galera (2016) e Nu bai. O rap negro de Lisboa (2007). E-mail: otavio_raposo@iscte-iul.pt.

Licença de uso. Este artigo está licenciado sob a Licença Creative Commons CC-BY. Com essa licença você pode compartilhar, adaptar, criar para qualquer fim, desde que atribua a autoria da obra. 